\title{
ALGUNAS CONSIDERACIONES METODOLÓGICAS A PROPÓSITO DE LA NUEVA RELACIÓN ENTRE ESTADO, DERECHO Y JUSTICIA SOCIAL EN EL CONSTITUCIONALISMO DE MERCADO EUROPEO
}

\author{
Ainhoa Lasa López \\ Doctora en Derecho \\ Universidad del Pais Vasco
}

\begin{abstract}
Sumario. 1. Aproximación preliminar al estado de la cuestión. 2. La constitución material como presupuesto metodológico. 3. La constitución material del Estado social. 4. La nueva constitución material y sus coordenadas. 4.1. La constitución económica europea. 4.2. Constitucionalismo económico de mercado c. Constitucionalismo económico social. 4.3. La justicia social competitiva. 4.4. El modelo social europeo. 4.5. El papel de los principios fundamentales del ordenamiento europeo- libertades económicas y competencia- en las decisiones del juez europeo. 5. Consideraciones finales.
\end{abstract}

\section{APROXIMACIÓN PRELIMINAR AL ESTADO DE LA CUESTIÓN.}

Las novedades registradas en las últimas décadas en el ordenamiento europeo han introducido un escenario de reflexión con respecto al constitucionalismo del Estado social. Concretamente, la contradicción entre un constitucionalismo gestado en el proceso de construcción del Estado social y la nueva realidad constitucional que plantea la integración europea. Desde esta perspectiva, cierto sector doctrinal ha evidenciado la tensión entre la Constitución formal del Estado social y las transformaciones que incorpora la Unión Europea, situando el punto de confluencia en la desaparición de la constitución material del Estado social. Formulaciones que rescatan la doctrina mortatiana sobre la constitución material como mecanismo de resolución de la paradoja descrita ${ }^{1}$. La pervivencia formal de las constituciones del constitucionalismo social en el marco de la transición hacia una nueva forma de Estado, que tiene en la nueva constitución material postsocial la superación de la contradicción apuntada.

El proceso de integración europeo entra en un nuevo periodo en su historia a partir del Tratado de Maastricht, tal y como se ha reconocido desde la propia doctrina comunitaria ${ }^{2}$. Desaparece la inicial autonomía del espacio

${ }^{1}$ AAVV., La costituzione materiale: percorsi culturali e attualitá di un'idea, en A. Catelani \& S. Labriola (a cura di), Quaderni di Rassegna Parlamentare, Giuffré, Milano, 2001.

2 Poiares Maduro, M., «Europe's Social self: 'the sickness unto death'», disponible en: http:/lesl.man.ac.uk/conweb, n. 2. 2002. 
estatal en su relación con el ordenamiento jurídico europeo que permitía una cierta convivencia entre modelos contrapuestos, el estatal vinculado al Estado social, y el proyecto europeo dirigido a garantizar la centralidad del mercado primero común, y después interior ${ }^{3}$. Como consecuencia de esta ruptura, se produce una infiltración de los principios del mercado en el sistema de valores propio del constitucionalismo social ${ }^{4}$. La tensión entre el modelo del constitucionalismo social y el europeo, aunque ya presente desde los inicios de la integración, alcanza en esta fase del proceso su máxima expresión ${ }^{5}$.

Esta primacía del vínculo económico se consolida en el último referente normativo, el Tratado de Lisboa, que reproduce los contenidos del heterogobierno del mercado y el primado de la economía vigentes desde los Tratados Constitutivos de las Comunidades Europeas. De hecho, la actuación de objetivos sociales que contempla el nuevo artículo 3 del Tratado de Lisboa, la economía social de mercado altamente competitiva, tendente, al pleno empleo y al progreso social, lejos de introducir principios contradictorios con las características del modelo económico originario que permitan recuperar una cierta continuidad con el constitucionalismo económico del Estado social, sancionan la herencia del constitucionalismo de mercado.

Si nos fijamos en el contexto del elenco de la definición de objetivos, nos encontramos con que los presupuestos que legitiman una supuesta integración positiva en el mercado interior consistente en la equiordenación entre objetivos económicos y sociales, son deficitarios. Por un lado, porque los objetivos establecidos en el artículo 3 del Tratado de la Unión (TUE) están condicionados por los instrumentos contemplados para su realización, es decir, son los instrumentos los que determinan el verdadero alcance de los objetivos. El mercado interior y la Unión Económica y Monetaria (UEM), así como las políticas del artículo 119 del Tratado de Funcionamiento de la Unión Europea (TFUE). Si los medios determinan los objetivos de la Unión, es necesario contextualizar el artículo 3 del TUE con el artículo 119 del TFUE. En ambos la centralidad del mercado es incuestionable. «La economía de mercado abierta y de libre competencia» impone la decisión de principio del sistema que condiciona y preside el ordenamiento jurídico europeo. Por lo tanto, los instrumentos determinan el alcance de los fines. Los objetivos de la Unión sólo tienen espacio para su realización en base a su compatibilidad con los principios del mercado y la UEM.

${ }^{3}$ Scherer, J., Die Wirtschaftsverfassung der EWG. Schriftenreiche Europäische Wirtschaft, Nomos Verlagsgesellschaft, Baden-Baden, 1970, p. 83.

${ }^{4}$ Orlandini, G., «Mortati, il lavoro e la Costituzione che non c'é piú», en L. GaEta (a cura di), Atti della Giornata di Studio. Siena, 31 gennaio 2003, Constantino Mortati e 'Il lavoro nella Costituzione': una rilettura, Giuffré, Milano, 2005, p. 219.

5 JoERGES, Chr., «What is left of the European economic constitution», EUI WP LAW 13/2004. 
Por otro lado, porque es el propio artículo 119 del TFUE el que resuelve la tensión entre los objetivos en conflicto al establecer la verdadera relación entre ellos. La preeminencia de los objetivos económicos se deriva de la propia dicción del precepto vinculada a la definición de una constitución económica distinta de la que sugieren quienes pretenden recuperar con el Tratado de Lisboa a la constitución económica del vínculo social. De tal modo que lo que se establece es una relación jerárquica que determina la primacía de los objetivos económicos sobre los sociales. Estos últimos situados en una posición de compatibilidad subalterna, confirman la definición del modelo de constitución económica del vínculo económico. Por eso, el nuevo artículo 3 confirma la ruptura de la dinámica político institucional del Estado social ${ }^{6}$.

Paralelamente, los objetivos sociales previstos no tienen los efectos intervencionistas que determinarían la metamorfosis del modelo, sino todo lo contrario, porque de lo que se trata es de garantizar el mercado consolidando su centralidad. La remercantilización del vínculo social en la esfera europea persigue la captación de espacios antes sustraídos a las dinámicas del vínculo económico incorporando, como veremos, el principio de la competencia y la centralidad del mercado en la definición de la dimensión social europea.

En este sentido, el progresivo desmantelamiento de las bases que conforman al Estado social constitucionalizado en los textos fundamentales de la segunda posguerra, ejemplifica la confrontación entre la constitución formalmente vigente y la nueva realidad que desnaturaliza los contenidos de la forma de Estado que contemplan estas constituciones. Es decir, en el ámbito estatal, la crisis del Estado social en la realidad no se ha reflejado todavía en las constituciones que mantienen formalmente el constitucionalismo del Estado social, produciéndose de esta manera una situación contradictoria realidad-constitución ${ }^{7}$. Lo que pone de relieve que el actual momento constitucional plantea la necesidad de buscar orientaciones metodológicas que ayuden a la comprensión de la confrontación descrita.

En esta perspectiva se sitúan aquellos planteamientos en los que como se ha señalado, el análisis de la relación Unión Europea-Estados miembros tiene en la crisis de la constitución material de las constituciones nacionales, el elemento determinante de sus argumentaciones ${ }^{8}$. De acuerdo con estas propuestas, la utilidad de la constitución material tiene la virtualidad de comprender y resolver la contradicción entre los ordenamientos constitucio-

${ }^{6}$ Maestro Buelga, G., «El Tratado de Lisboa y la Constitución económica», Revista Española de Derecho Constitucional Europeo, n. ${ }^{\circ}$ 9, 2008, p.39.

7 De CABo, M., «Tratado Constitucional europeo y constitucionalismo del Estado social», Teoría y Realidad Constitucional, n. ${ }^{\circ}$ 19, 2007, p. 204.

${ }^{8}$ Bilancia, F., «Brevi note su costituzione materiale, legalitá ed Unione Europea», en A. Catelani \& S. Labriola (a cura di), Quaderni di Rassegna Parlamentare, La costituzione materiale: percorsi culturali e attualitá di un'idea, Giuffré, Milano, 2001, pp. 425 ss. 
nales formales nacionales y el europeo. Así, éste último formaliza principios opuestos a la tradición del constitucionalismo social, consagrando y sancionando normativamente lo que en el ámbito de los Estados miembros está en la nueva constitución material pero, no en la Constitución. A través de los principios de primacía y efecto directo, el nuevo paradigma se infiltra en los ordenamientos nacionales resolviendo la contradicción.

La trasformación de la constitución material de los Estados miembros en una nueva se realiza desde la instancia europea que disciplina de esta manera a los ordenamientos internos, restableciendo la continuidad entre constitución formal y constitución material en el nivel europeo. Por lo tanto, es en este nivel donde se gesta la nueva constitución material que simboliza la ruptura con la del Estado social. Y es precisamente también en este nivel, donde se desarrolla la unificación entre la nueva constitución material y el constitucionalismo compuesto superando la tensión normativa existente entre las constituciones formales nacionales del Estado social y la nueva constitución material ${ }^{9}$.

\section{La constitución material como presupuesto metodológico.}

La ruptura de la constitución material del Estado social hace necesario, siquiera brevemente, abordar los elementos esenciales de la misma como punto de partida para su confrontación con los que se reconocen en la nueva constitución material. En este contexto, la referencia a la construcción de Mortati resulta obligada. Tal y como se ha puesto de relieve, la utilidad de su propuesta metodológica reside en la conexión que ésta establece entre constitución formal y realidad material. Alejado del formalismo purista de la corriente kelseniana que se sustanciaba en una concepción exclusivamente formal y legal del derecho, y de la corriente pandectística, como tendencias dominantes en el pensamiento jurídico de los primeros tiempos del siglo diecinueve, el autor plantea la necesidad de recuperar la unidad en la pluralidad y de unificar en el ámbito jurídico espacios que hasta ese momento habían permanecido separados ${ }^{10}$.

Al mismo tiempo, su novedosa aproximación al derecho constitucional a través de su necesaria vinculación con las exigencias sociales en las que encuentra su razón de ser, supuso un tratamiento del derecho constitucional como fuente de integración, legitimación y garantía, frente al derecho constitucional liberal como simple expresión de la lógica y de la racionalidad ${ }^{11}$.

${ }^{9}$ Labriola, S., «Costituzione materiale e transizione», en A. Catelani \& S. Labriola (a cura di), Quaderni di Rassegna Parlamentare. La costituzione materiale: percorsi culturali e attualitá di un 'idea, Giuffré, Milano, 2001, pp. 239 ss.

${ }^{10}$ Mortati, C., La costituzione in senso materiale, Giuffré, Milano,1998, pp. 129132.

${ }_{11}$ Pizzetti, F., «Costituzione materiale e Costituzione formale tra passasto, presente e futuro», en A. Catelani \& S. Labriola (a cura di), Quaderni di Rassegna Parlamentare. La 
El aspecto más relevante de la construcción consiste en articular la unificación del ordenamiento en base a un fundamento material previo a la norma constitucional que se desarrolla en una triple dirección. En primer lugar, la constitución material garantiza la validez de la constitución formal; en segundo lugar, garantiza la unidad del ordenamiento jurídico descrita y, en tercer lugar, el fin es unitario porque la constitución material lo define de manera vinculante ${ }^{12}$.

Sobre estas bases se construye la propuesta mortatiana que lejos de suponer una ruptura de la unidad del texto constitucional despojándolo de toda normatividad ${ }^{13}$, realiza precisamente la premisa opuesta. «Contrariamente a cuantos sospechan las interpretaciones vanalizantes de la constitución material, el fin al que ésta se dirige, no es minar la fuerza de la constitución formal, sino exactamente lo contrario, sostenerla con su fuerza material $\rangle^{14}$. Por lo tanto, la relación entre ambas constituciones, material y formal, no es contradictoria sino instrumental de la segunda para con la primera que tiene en ésta su fuente de validez.

La primacía de la constitución material de la que se deriva la constitución formal impide la contradicción entre ambas, estableciendo un vínculo de garantías recíprocas. La constitución formal concretiza la generalidad de los contenidos de la constitución material, lo que implica su autonomía. Esta relación, autonomía de la constitución formal-primacía de la constitución material, es especialmente visible en las situaciones de normalidad constitucional, dado que la primacía de la constitución material se atenúa. Por el contrario, en los momentos de ruptura de los principios que configuraban a la constitución material preexistente, la normatividad de la constitución formal retrocede, en la medida en que se muestra incapaz de desplegar sus efectos disciplinantes en el ordenamiento jurídico como consecuencia de la preeminencia de la nueva constitución material ${ }^{15}$.

costituzione materiale: percorsi culturali e attualitá di un'idea, Giuffré, Milano, 2001, pp. 409-420. CATElani, A., «La costituzione materiale e il diritto vivente», en A. CATELANI \& S. Labriola (a cura di), Quaderni di Rassegna Parlamentare. La costituzione materiale: percorsi culturali e attualitá di un 'idea, Giuffré, Milano, 2001, pp. 53-71. CATANIA, A., «Mortati e Schmitt», en A. Catelani \& S. Labriola (a cura di), Quaderni di Rassegna Parlamentare. La costituzione materiale: percorsi culturali e attualitá di un'idea, Giuffré, Milano, 2001, pp. 109-128. Pecora, G., «Mortati e Kelsen», en A. Catelani \& S. Labriola (a cura di), Quaderni di Rassegna Parlamentare. La costituzione materiale: percorsi culturali e attualitá di un 'idea, Giuffré, Milano, 2001, pp. 139-157.

12 Mortati, C., La Costituzione in senso materiale, op. cit., pp. 124-132.

13 Jiménez CAmpo, J., «Contra la constitución material», Estudios de Derecho Público. Homenaje a Juan José Ruiz Rico, Vol. I, Tecnos, Madrid, 1997, pp. 42-54.

${ }^{14}$ Zagrebelsky, G., «Premessa a la Costituzione in senso materiale», La costituzione in senso materiale, Giuffré, Milano, 1998, p. XXXV.

15 Mortati, C., «Voz 'Costituzione (dottrine generali)», Enciclopedia del Diritto, vol. XI, Giuffré, Milano, 1962, pp. 139 ss. 
Desde esta orientación, es posible comprender las transformaciones que se están produciendo desde la década de los ochenta, materializadas en una sintomatología de conflicto entre los enunciados formalmente constitucionalizados y la nueva realidad constitucional. Frente al formalismo positivista que repropone el tema de la separación entre derecho y realidad, y donde la constitución se interpreta de acuerdo con una concepción exclusivamente formal que la habilita para poder permanecer ajena a las nuevas realidades sociales que tienen lugar.

Las insuficiencias de esta última aproximación se evidencian claramente en los momentos de desarmonía entre orden legal y orden político, y conducen precisamente a cuestionar la propia vigencia del enunciado formal. Desde estas posiciones, la resolución del conflicto se manifiesta en la propia quiebra formal de los supuestos sobre los que se construía el Derecho constitucional. El resultado es la neutralización técnica del Derecho constitucional, su consideración puramente instrumental que se traduce en su reducción a procedimiento como respuesta sistémico-funcional al conflicto ${ }^{16}$.

Precisamente, la celebrada Constitución como forma dat esse rei, «ha alcanzado grados de flexibilidad altísima, toda reivindicación de la misma, de su aplicación (guardada con ansia y realizada), es una reivindicación no tanto de su forma como de su función. Justamente a su lado, la ciencia del derecho corre a camuflarse como ciencia funcionalista. Funcionalismo y 'ciencia alternativa' llegan incluso a confundirse, de tal suerte que hoy puede leerse un juego distinto y variado entre estructura y superestructura hasta en los planteamientos más formales ${ }^{17}$. De manera que siguiendo la orientación mortatiana, podemos decir que la constitución formal desconectada de la idea de constitución material implica la propia devaluación del texto constitucional que termina, a su vez, por imponer una lectura débil de la constitución.

Paralelamente, en el discurso de Mortati adquiere relevancia el momento de gestación de la doctrina de la constitución material. En particular, la construcción de la teoría se produjo en un momento de crisis y transición que obligaba a una reflexión en la que tales aspectos adquirían una relevancia central. La crisis del Estado liberal se sitúa como el punto de partida de la constitución material y su conexión con la nueva forma de Estado que comienza a gestarse. La forma de Estado actúa como el elemento determinante de la constitución material. Con ésta se busca la armonía o unidad de la organización social, teniendo en cuenta en todo momento la necesidad de un nuevo imaginario o modelo antropológico para hacer frente a los problemas que inauguraban el nuevo ciclo constitucional ${ }^{18}$.

${ }^{16} \mathrm{De}$ CABo, C., «Encuesta sobre la orientación actual del derecho constitucional», Teoría yRealidad Constitucional, n. ${ }^{\circ}$ 1, 1998, p. 19.

17 Negri, A. «Del capital a los Grundrisse», La Forma-Estado, Akal, Madrid, 2003, p. 15.

18 Bergareche Gros, A., «La Constitución en sentido material de Constantino Mortati. Estudio Preliminar», La Constitución en sentido material de Constantino Mortati, Centro de Estudios Políticos y Constitucionales, Madrid, 2000, pp. IX-XV. 
En la identificación de los contenidos de la nueva forma de Estado que la diferencian de la precedente, se encuentra la respuesta a la definición de la constitución material. La forma de Estado implica por tanto, el reenvío material de la norma constitucional. Frente a la forma de Estado liberal que niega en su formalización el conflicto capital-trabajo, éste concepto adquiere una dimensión sustancialmente distinta en el Estado social. La ruptura de la separación de las esferas de la política y de la economía introduce en el Estado social el conflicto tanto en la determinación de su contenido como en su expresión constitucional.

Con su formulación del Estado social, Mortati sitúa a la integración del trabajo en el centro del Estado social que se contrapone de esta manera al orden liberal excluyente. Centralidad del trabajo sobre la que se define la forma de Estado social, convirtiéndose en el valor fundamental de los principios jurídicos que predeterminan los contenidos de la nueva forma de Estado constitucionalizada ${ }^{19}$. Así, el Estado social es una nueva forma de Estado que supone una quiebra del Estado liberal cuyos caracteres están configurados por las nuevas interrelaciones entre los niveles socioeconómico y político.

\section{LA CONSTITUCIÓN MATERIAL DEL ESTADO SOCIAL.}

La constitución económica del Estado social constituye el paradigma de la materialización de las transformaciones que incorpora el Estado social. El cambio en las funciones del Estado, especialmente en los ámbitos económico y social que dejan de configurarse como esferas incontaminadas, hace que ahora ambas definan las condiciones materiales de esta forma de Estado. No en vano, en la formulación de Mortati la conexión constitución material-forma de Estado representa el elemento delimitador de la constitución económica $^{20}$ que adquiere una doble dimensión, conflictual y garantista ${ }^{21}$. La primera se refiere al espacio de disponibilidad confiado al desarrollo del conflicto. Los derechos sociales reflejan en su estructura la vinculación con la dimensión conflictual de la constitución material. La dimensión disponible de los derechos revela el estatus constitucional débil de los derechos sociales $^{22}$ que se combina con la dimensión de garantía, en la que se establece el reconocimiento de los protagonistas del conflicto distributivo. Este reconocimiento implica la institucionalización del conflicto que preservando el estatus del trabajo en el desarrollo del mismo, permite al mismo tiempo

19 Mortati, C., «Il lavoro nella Costituzione», en L. Gaeta (a cura di), Constantino Mortati e il lavoro nella Costituzione: una rilettura, Atti della Giornata di Studio, Siena, 31 gennaio 2003, Giuffré, Milano, 2005, p. 8.

${ }^{20}$ Mortati, C., Le forme di Governo, Cedam, Padova, 1975, pp. 39 ss.

21 De Cabo Martín, C., La crisis del Estado social, PPU, Barcelona, 1986, pp. 28-30.

22 Barcellona, P., «Diritti sociali e corte costituzionale», Rivista giuridica del lavoro e della previdenza sociale, . $^{\circ}$ 3, 1994, pp. 325-331. 
actuar el conflicto dentro de los límites definidos en el compromiso en torno al que se funda el Estado social.

Por lo tanto, los contenidos de la constitución material del Estado social especifican el reenvío político social de la constitución afectando tanto a la constitucionalización de los sujetos del conflicto, como al establecimiento del sistema de garantías recíproco, la definición del conflicto y sus límites. La integración se produce en un doble plano político y económico. El primero reconoce la subjetividad política de los sujetos del conflicto social. La garantía del privado y del mercado supone el establecimiento de límites a la intervención distributiva de los poderes públicos, el control político estatal de los resultados espontáneos del conflicto se produce ex post, compensando las desigualdades socioeconómicas. Paralelamente al límite impuesto al trabajo de no modificación de las bases del capitalismo, opera un límite al conflicto dirigido a preservar el fundamento material de la integración o equilibrio relacional entre el capital y el trabajo que define la integración económica.

Este planteamiento permite vincular la constitución económica al Estado social que actúa como referente de las disposiciones relativas a la actividad económica. De tal forma que la constitución económica del Estado social tiene su fundamento legitimador en la preeminencia normativa de las disposiciones vinculadas a la forma de Estado. Estas disposiciones se materializan en la configuración del Estado social como la decisión fundamental que impone una relación de funcionalidad con las disposiciones que articulan la constitución económica ${ }^{23}$.

Al mismo tiempo, conectar la constitución económica con la forma de Estado social supone la remisión a un modelo constitucionalmente determinado que impide la consideración autónoma de la constitución económica. Esta concepción de la constitución económica del Estado social como prescriptiva, permite deducir del complejo de principios constitucionales vinculados a esta forma de Estado, un sistema de relaciones económicas caracterizadas por el gobierno del mercado que se manifiesta en una serie de límites a las libertades económicas privadas constitucionalmente reconocidas. En definitiva, un dispositivo que posibilita la introducción en el ámbito privado de una lógica distinta a la de la estrategia de la acumulación, y se materializa en el primado de la política derivado del Estado pluriclase ${ }^{24}$.

Por lo que respecta al segundo de los elementos de la constitución económica del Estado social, el vínculo social como fuente de definición y límite

${ }^{23}$ CAntaro, A., «El declive de la constitución económica del Estado social», en M. A. García Herrera (dir), El constitucionalismo en la crisis del Estado social, Universidad del País Vasco, Bilbao, 1997, pp. 162-168.

24 Mortati, C., «Principi fondamentali (art. 1-12)», en G. Branca (a cura di), Commentario della Costituzione, Zanichelli, Roma, 1975, pp. 2-20. Mortati, C., Le forme di governo. Lezioni giuridiche, Cedam, Padova, 1973, pp. 428-445. 
al mercado, Mortati establece sus bases en torno a la centralidad del trabajo como fuente de legitimidad de la intervención de los poderes públicos en el sistema económico. El trabajo como principio organizativo en la definición normativa de los objetivos y límites de las actividades económicas ${ }^{25}$.

Esta reflexión sobre la constitución económica del Estado social se contrapone a la propuesta mayoritaria en la actualidad que destaca el carácter meramente descriptivo de la constitución económica del Estado social. Basada en la jurisprudencia del Alto Tribunal Alemán en torno a la expresión «neutralidad constitucional», consiste en una lectura flexible que partiendo de la ausencia de un modelo económico constitucionalizado propicia una pluralidad de modelos económicos que tienen sus límites en las libertades económicas configuradas como derechos constitucionales fundamentales. La aproximación a la cláusula de Estado social se efectúa en clave normativa lo que implica una desvalorización de esta cláusula en conexión con la forma de Estado. Desde esta lectura, el Estado social se configura como un principio jurídico que impide derivar efectos relevantes del dictado constitucional $^{26}$.

Tampoco la doctrina española se ha sustraído a estas consideraciones. Nos encontramos con una interpretación revisada de la cláusula de Estado social con efectos disciplinantes en la definición constitucional. De hecho, la singularidad del momento histórico caracterizado por el cuestionamiento de las bases teóricas y la viabilidad del gobierno público de la economía que acompañó al proceso constituyente español, tuvo implicaciones en cuanto al potencial de la cláusula Estado social en el ámbito de las relaciones políticaeconomía. La sugestiva adecuación de nuestra Carta Magna a la realidad socio-económica del momento parecía propiciar una desnaturalización de la cláusula social que pronto confirmaron determinados sectores de la doctrina ${ }^{27}$.

En todo caso, lo característico de esta propuesta es que la constitución económica se desvincula de la forma de Estado para configurarse como un sistema autónomo del enunciado constitucional o realidad extraconstitucional, en la que se permite la convivencia de principios contradictorios con el proyecto del constitucionalismo social.

${ }^{25}$ Mortati, C., «Il diritto al lavoro secondo la Costituzione della Reppublica. Natura giuridica, efficacia, garanzie», Problemi di diritto pubblico nell'attuale esperienza costituzionale repubblicana, Raccolta di Scritti-III, Giuffré, Milano, 1972, pp. 144-146.

26 Stober, R., Derecho administrativo económico, Ministerio para las Administraciones Públicas, Madrid, 1992, pp. 69 ss.

27 ArIÑo, G., «La constitución económica», La Constitución española de 1978, Tomo X, EDR, Madrid, 1985, pp. 3-22. Martín-Retortillo, S., «Constitución y constitucionalismo hoy», Cincuentenario del derecho constitucional comparado de Manuel GarcíaPelayo, Libris, Caracas, 2000, p. 169. 
Esta desvinculación de la forma de Estado en el análisis de la constitución económica atenúa los efectos jurídicos del principio constitucional, situando el discurso en términos de continuidad e impidiendo que el análisis se traslade a un plano de confrontación entre modelos.

La elasticidad sin fin de esta formulación permite una transición tranquila hacia los nuevos principios económicos expresados por la constitución económica europea, sustrayéndose a la confrontación entre el Estado social y la nueva constitución económica. En ese sentido, la propuesta doctrinal comentada desnaturaliza la formulación constitucional del Estado social a través de una flexibilidad interpretativa casi ilimitada que posibilita a su vez, la caracterización de la nueva constitución económica como una consecuencia natural de la evolución del sistema que no se confronta con la regulación económica del constitucionalismo social.

Por el contrario, el planteamiento metodológico que se sigue en estas páginas es el que conecta Estado social y constitución económica. Los contenidos de la constitución económica del Estado social son los vínculos impuestos por esta forma de Estado y se materializan en la ruptura de la autonomía del vínculo económico. La desaparición de los vínculos sociales al mercado es paralela a la centralidad de este último en la definición de la intervención en los ámbitos social y económico. Esta circunstancia no sólo implica la contradicción entre el mercado y los límites de los vínculos del constitucionalismo social, sino sobre todo el establecimiento de una nueva constitución económica.

\section{LA NUEVA CONSTITUCIÓN MATERIAL Y SUS COORDENADAS.}

La identificación de la constitución material del Estado social resulta imprescindible para su confrontación con la gestada en el periodo de ruptura de esta forma de Estado. Aunque determinar los contenidos de esta última encierra dificultades, podemos destacar algunas manifestaciones de ruptura que ilustran la modificación de la constitución material del Estado social. A este respecto merece la pena poner de relieve aquellas orientaciones en las que se identifica a la Unión Europea como sujeto de la nueva constitución material ${ }^{28}$.

Como se ha señalado, especialmente con el Tratado de Maastricht, la Unión Europea se configura como el ámbito normativo desde el que se sanciona la ruptura de los vínculos sociales al mercado que se establecen en el Estado social. La definición de la intervención social por y desde el mercado establece una nueva centralidad que implica la contradicción entre el vínculo económico y la integración del conflicto, estableciendo las bases de la nueva realidad material caracterizada por la centralidad del mercado. En

${ }^{28}$ Azzariti, G., «La costituzione materiale e le forze politiche dominante», en A. Catelani \& S. Labriola (a cura di), Quaderni di Rassegna Parlamentare. La costituzione materiale: percorsi culturali e attualitá di un'idea, Giuffré, Milano, 2001, pp. 300-301. 
este sentido, se ha señalado que el Tratado de la Unión representa el fin del Estado keynesiano, y la definitiva consolidación en el espacio transnacional europeo del modelo económico «Estado regulador» ${ }^{29}$. Un modelo sancionado en el actual Tratado de Lisboa.

Sin embargo, es la progresiva constitucionalización del ordenamiento jurídico europeo lo que permitirá la sustracción a los condicionamientos del constitucionalismo social de los Estados miembros. Más aún, es el carácter supranacional del ordenamiento jurídico europeo junto a su configuración constitucional, lo que permite la determinación del nuevo orden político. La configuración de un ordenamiento autónomo como sistema orgánico capaz de superponerse a los Estados miembros y sobre todo, al constitucionalismo económico que emanaba de las constituciones nacionales vinculadas al Estado social, era una exigencia inherente a la propia construcción del mercado europeo. Lo que requería en primer lugar, mutar los orígenes internacionalistas de la Comunidades Europeas ${ }^{30}$. De hecho, la construcción jurisprudencial de la CEE como ordenamiento supranacional (STJCE. As. C-6/1964 Costa-Enel), y las referencias en la jurisprudencia a la exigencia funcional de esta construcción para la construcción del mercado común ${ }^{31}$, explican la calificación de los Tratados como Constitución comunitaria en base a las exigencias de los objetivos de la Comunidad ${ }^{32}$.

No obstante, aunque el empleo del término Constitución haya encontrado resistencias en el debate europeo ${ }^{33}$, lo relevante es que este proceso de

${ }^{29}$ La Spina, A. \& Majone, G., Lo stato Regolatore, Il Mulino, Bologna, 2000, pp. 20-35.

${ }^{30}$ Ciciriello, M. C., La Comunitá Europea e i suoi principi giuridici. Lezioni di diritto comunitario, Scientifica, Napoli, 2004, pp. 37 ss. Catelano, N. \& Scarpa, R., Principi di diritto comunitario, Giuffré, Milano, 1984, pp. 16-17.

31 Sentencia del Tribunal de Justicia de las Comunidades Europeas de 5 de febrero de 1963, As. C-26/62 Van Gend en Loos. Para un análisis más detallado sobre el papel central desempeñado por el TJCE en el proceso de constitucionalización del orden europeo: Fernández Esteban, M. L., «La Corte di Giustizia quale elemento essenziale nella definizione di Costituzione Europea», Rivista Italiana di Diritto Pubblico Comunitario, n. ${ }^{\circ}$ 2. 1996, pp. 221-238.

32 Pescatore, P., «Les objectifs de la Comunauté Européeenne comme principes d'interprétation dans la jurisprudence de la Cour de Justice», en Miscellanea W.J. Gansfhof van der Meerssoh. Vol. II, Bruxelles, 1972, p. 362. Kotzur, M., «Los objetivos de la Unión. Una contribución a la identidad y finalidad constitucional de la Unión Europea», Revista de derecho constitucional europeo, n. ${ }^{\circ} 2,2004$, pp. 35 ss.

${ }^{33}$ Desde estas posiciones sólo tendría sentido hablar de Constitución europea en sentido descriptivo debido a la ausencia de una voluntad constituyente. A tal efecto se señala que «la expresión empleada por el Tribunal de Justicia de las Comunidades al referirse a los Tratados europeos en términos de 'carta constitucional', se limitaría a poner de relieve que en el ámbito del ordenamiento comunitario los Tratados son una ley superior pero, no necesariamente que se esté en presencia de una Constitución». Anzon, A., «La 
constitucionalización del ordenamiento de la Unión coincide cronológicamente con los primeros síntomas de desgaste del Estado social. A mediados de los setenta, el Tribunal de Justicia de las Comunidades Europeas inaugura el ciclo de pronunciamientos judiciales en los que se refiere a los Tratados Comunitarios como Constituciones europeas. En particular, con la sentencia Les Verts/ Parlamento Europeo (As. C-249/83), el juez comunitario establece el principio de acuerdo con el cual, «la Comunidad Económica Europea es una Comunidad de derecho, en el sentido que ni los Estados que forman parte de la misma, ni sus instituciones están sustraídos al control de conformidad de sus actos con la carta constitucional de base constituida por el Tratado» (Considerando 23).

La Comunidad como Comunidad de derecho despliega sus efectos de legitimación y control interno salvaguardando la decisión política fundamental del ordenamiento europeo, «economía abierta y de libre competencia» ${ }^{34}$. Bases normativas que permiten la unificación del ordenamiento jurídico europeo y los ordenamientos nacionales superando la tensión entre la constitución formal nacional vinculada al constitucionalismo social, y el ordenamiento europeo vinculado al constitucionalismo de mercado.

La formulación de la constitución compuesta ${ }^{35}$ teoriza el momento unificador descrito. Sin embargo, conviene establecer algunas precisiones a propósito de sus presupuestos. En primer lugar, los defensores de la propuesta niegan la presencia de jerarquía entre los distintos niveles, el comunitario como sistema único, que a su vez está compuesto por la Unión y los Estados. «No hay a priori supremacía ni del derecho europeo ni de las constituciones nacionales. El simple hecho de que la constitución europea se inspire y comprenda a las constituciones nacionales, o se base en la voluntad común de los ciudadanos de todos los Estados Miembros, no implica como tal jerarquía alguna $\rangle^{36}$.

No obstante, y en segundo lugar, en la medida en que desde la teoría de la constitución compuesta se postula la unitaria consideración del ordenamiento compuesto, «ambos sistemas legales coexisten pero como parte de un único sistema que tiene que producir en último término una única

Costituzione europea come problema», en A. D’Antena \& E. Lancillota (a cura di), Da Omero alla Costituzione europea. Costituzionalismo antico e moderno, Tored, Roma, 2003, p. 308.

${ }^{34}$ Cantaro, A., Europa sovrana, Dedalo, Bari, 2003, pp. 71 ss.

35 Pernice, I., «Multilevel constitucionalism and the Treaty of Amsterdam. European constitution-making revisited?», Common Market Law Review, Vol. 36, n. ${ }^{\circ}$ 4. 1999, pp. 703-750. CASSESE, S., «L'Unione Europea come organizzazione pubblica composite», Rivista italiana di diritto pubblico comunitario, n. ${ }^{\circ}$ 5, 2000, pp. 987-993.

36 Pernice, I., «Multilevel constitucionalism in the European Union», European Law Review, n. ${ }^{\circ} 27,2002$, p. 520. 
respuesta legal para cada caso» ${ }^{37}$, se impone inevitablemente la absorción del constitucionalismo de los Estados miembros por el constitucionalismo de mercado europeo.

Sobre la base de la primacía de la Constitución Europea se resuelve la confrontación entre constitucionalismo social y ordenamiento europeo que se disuelve normativamente. El derecho del conglomerado de la integración ha realizado la transformación en un orden jerárquico ${ }^{38}$ que actúa con efectos absorbentes sobre el constitucionalismo nacional. En particular, desde el orden del mercado se realiza la transformación del constitucionalismo social estatal resolviendo la contradicción normativamente ${ }^{39}$.

\subsection{La constitución económica europea.}

La constitución económica europea es el paradigma de las transformaciones introducidas por la nueva realidad constitucional europea. Si la constitución económica del Estado social representa el principal ámbito de materialización de las transformaciones incorporadas por esta forma de Estado, la constitución económica europea se erige como el paradigma de los cambios demandados desde la estancia europea que se caracterizan por su oposición y ruptura con los del Estado social. De hecho, desde sus inicios el proceso de integración europeo nació con vocación de ruptura de los vínculos sociales al mercado introducidos por el Estado social.

La ausencia de un dispositivo social en los Tratados Constitutivos de las Comunidades Europeas lejos de obedecer a un descuido intencional o a un «marxismo preterintencional de los padres fundadores ${ }^{40}$, tiene su leif motiv en la decisión política fundamental asumida por los Tratados originarios, y que perdura en la actualidad, de dar vida a una economía abierta y de libre competencia. La recepción normativa de este objetivo se vio complementada con la articulación de una serie de mecanismos dirigidos a su tutela y garantía que se traducían en una desnaturalización y desconstitucionalización a escala europea de los principios constitucionales adscritos al Estado social.

La constitución y garantía del vínculo económico en detrimento del primado de la política constituye el referente exclusivo y excluyente del proyecto de integración. La centralidad del vínculo económico determinante del imperativo constitucional europeo del mercado primero común y después interior, es el soporte desde el que se articulan las nuevas relaciones fruto del proyecto de la integración europea. Por lo tanto, la falta inicial de

37 Pernice, I., «Multilevel constitucionalism in the European Union», op.cit., p. 520.

38 Nettesheim, M., «El significado constitucional de la primacía del derecho comunitario/de la Unión», Revista española de derecho europeo, n. ${ }^{\circ}$ 6, 2003, p. 285.

39 Maestro Buelga, G., «El Tratado de Lisboa y la Constitución Económica», op.cit., pp. 54-56.

40 Alarcón Caracuel, M.R., «La necesitá di un capitolo sociale nella futura Costituzione Europea», Lavoro e Diritto, Vol. 4, 2000, pp. 608-609. 
medidas normativas que se materializaran en una intervención correctora y consiguiente condicionamiento del mercado, es funcional a la configuración del proceso europeo como proceso de afirmación de la centralidad y garantía del mercado ${ }^{41}$.

La autonomía del mercado es incompatible con el gobierno del mercado, y para preservar esta autonomía es necesario desmantelar los vínculos impuestos al sistema económico. La desaparición de estos vínculos lleva aparejada una nueva centralidad que no es otra que la centralidad del mercado en la definición de la intervención social y económica. Esto supone la ruptura del vínculo social como elemento que da forma a la constitución económica del Estado social, y su sustitución por el vínculo económico que se diferencia del primero tanto desde el punto de vista de su dimensión normativa, como del significado que otorga a los elementos estructurales del constitucionalismo social.

La nueva forma de articulación de las relaciones de poder entre la dimensión estatal y la económica como decisión política fundamental en torno a la que se articulan los valores y las instituciones en las que estos se materializan, sitúa al mercado como elemento nuclear que legitima a la nueva realidad constitucional. Todos aquellos valores que conectan con la centralidad del mercado (economía social de mercado, libre competencia, libertades económicas, competitividad, saneamiento y sostenibilidad presupuestarios) son valores que el modo de ser político de la Unión considera irrenunciables.

El nuevo compromiso del poder público en la tutela de la autonomía del mercado que incorpora el constitucionalismo de la Unión, actúa de límite a los vínculos del constitucionalismo social.

\subsection{Constitucionalismo económico de mercado c. Constitucionalismo económico social}

De acuerdo con el artículo 3 del TUE: «3.1. La Unión tiene como finalidad promover la paz, sus valores y el bienestar de sus pueblos. 3.2. La Unión ofrecerá a sus ciudadanos un espacio de libertad, seguridad y justicia sin fronteras interiores, en el que esté garantizada la libre circulación de personas (...). 3.3. La Unión establecerá un mercado interior. Obrará en pro del desarrollo sostenible de Europa basado en un crecimiento económico equilibrado y en la estabilidad de los precios, en una economía social de mercado altamente competitiva, tendente al pleno empleo y al progreso social (....)». Se establece además, que la Unión fomentará la cohesión económica, social y territorial y la solidaridad entre los Estados miembros».

Como puede observarse, ha desaparecido de entre los objetivos de la Unión «la competencia libre y no falseada» que figuraba en el artículo I-3.2 del Tratado Constitucional. Una de las principales exigencias durante la fase

${ }^{41}$ Hatje, A., «Wirtschaftsverfassung», en A. Von Bogdangy (dir), Europäisches Verfassungsrecht, Springer, Berlín-Heilderberg, 2003, pp. 744 ss. 
de negociación que esgrimió el gobierno francés, y que fue vista como un guiño a los electores franceses que rechazaron la Constitución en el referendo de 2005. No obstante, se trata de un cambio cosmético con escasas repercusiones jurídicas puesto que empleando una técnica legislativa ya ensayada con el Pacto de Estabilidad y Crecimiento (PEC), se recupera todo el impacto normativo del principio.

En concreto, en el punto 16 de las conclusiones presentadas por la Presidencia del Consejo ${ }^{42}$, se establece que se anexará al Tratado reformado un Protocolo sobre mercado interior y competencia que se configurará como el marco de referencia para la interpretación del nuevo artículo 3 del Tratado de Lisboa. «Las Altas Partes Contratantes, considerando que el mercado interior tal como se establece en el artículo 3 del Tratado de la Unión Europea incluye un sistema que garantiza que no se distorsione la competencia, han acordado que, para ello, la Unión deberá actuar, en caso necesario, con arreglo a las disposiciones de los Tratados, incluso con arreglo al artículo 308 del Tratado sobre el funcionamiento de la Unión».

De nuevo, la constitución económica europea condiciona el proceso europeo determinando su contenido. La comparación, incluso literal, de los Tratados con el texto de Lisboa, clarifica la centralidad de los postulados de la integración económica. Se confirma la preeminencia de la estabilidad de precios como principio rector para todas las instituciones de la Unión Europea cuando actúen en materia económica, y para los Estados miembros en la elaboración y aplicación de sus políticas nacionales y en la coordinación de estas últimas en el espacio europeo. Paralelamente, la referencia expresa al establecimiento de la UEM como objetivo básico de la integración económica (artículo 3.4 del TUE) reproduciendo la estructura de la gobernanza económica europea vigente desde el Tratado de Maastricht, consolida las garantías vinculadas a la tutela del mercado que condicionan a la dimensión social a su compatibilidad subalterna.

El propio artículo en su apartado tercero, rescata la expresión del nonato Tratado Constitucional «economía social de mercado altamente competitiva», que dista de representar un avance en el proceso de incorporación a la constitución económica europea de previsiones dirigidas a reequilibrar las relaciones entre la integración económica y la integración social. Más bien, ésta se articula en torno al paradigma de la «economía de mercado abierta y de libre competencia» como modelo económico del constitucionalismo de mercado europeo que determina los espacios para su realización. En particular, los poderes públicos intervienen al objeto de hacer compatibles las estructuras sociales con el libre y competitivo mercado concurrencial a través de la subordinación de las primeras al segundo.

La incorporación de la economía social de mercado tiene su origen en las propuestas del Grupo XI «Europa Social» y, en menor grado, en las del Gru-

${ }^{42}$ Conclusiones de la Presidencia-Bruselas, 21/22 de junio de 2007. 11177/1/07 REV1. 
po IV «Gobernanza económica» ${ }^{43}$. Desde un sector doctrinal se ha destacado que la interpretación de la expresión «economía social de mercado» por parte de estos grupos de trabajo era muy distinta. De hecho, el Grupo «Europa Social» no proponía la incorporación de este concepto ni en los mismos términos, ni con el mismo significado atribuido por el de la «Gobernanza económica». Concretamente, este último sugería en sus recomendaciones que los objetivos económicos y sociales quedaban recogidos en el Tratado constitucional, y que debían basarse en el contenido de los artículos 2, 3 y 4 del TCE (sustituidos por el artículo 3 del TUE, y por el artículo 119 del TFUE. Considerando, por lo tanto, que la economía social de mercado se manifiestaba como modelo en el contenido de estos preceptos.

Desde el Grupo «Europa Social» la propuesta se articulaba en términos muy diferentes. La economía social de mercado se configura como nexo de unión entre el desarrollo económico y social, vinculándola en el apartado segundo de su informe a la exigencia de «equiparación, y no de subordinación, entre los objetivos sociales y los objetivos económicos» ${ }^{44}$. De esta manera se manifiestaba el intento de reequilibrio entre dimensión social y económica en la integración europea. Pero todavía más, se consideraba que la fórmula «economía social de mercado» se confrontaba con la que se recogía en el artículo 4 del TCE, «economía de mercado abierta y de libre competencia» ${ }^{45}$.

La expresión finalmente incorporada fue muy distinta, limitando la interpretación aportada en las reflexiones del informe definitivo del Grupo XI. La acotación «altamente competitiva», completa a la economía social de mercado desnaturalizando el compromiso que incorporaba entre integración negativa e integración positiva en base a las apreciaciones de los integrantes del Grupo «Europa Social». La economía social de mercado altamente competitiva no se erige como paradigma definidor del modelo de constitución económica, sino que como ya adelantara el grupo de la gobernanza económica, su verdadero significado se desprende de su vinculación con el resto de disposiciones del Tratado.

Por ello, el nuevo dictado normativo debe de ponerse en relación con los preceptos de la política económica y monetaria. Disposiciones que se limitan a reproducir estas políticas tal y como estaban configuradas en el TCE, reconduciendo el modelo a la fórmula de la economía de mercado abierta y de libre competencia ${ }^{46}$. Se confirma la disposición de la gobernanza económica europea de Maastricht (artículos 119-133 del TFUE), en la que la

${ }^{43}$ CONV 357/02. Informe definitivo del Grupo IV «Gobernanza económica».

${ }^{44}$ CONV 516/1/03 REV 1, Informe final del Grupo XI «Europa Social», p. 8.

${ }^{45}$ CONV 516/1/03, op.cit., p. 10.

46 Miccú, R., «Finalismo dell’Unione ed economia sociale di mercato: modello (obsoleto) o 'principio di speranza' del costituzionalismo europeo», Diritto e Cultura, n. ${ }^{\circ}$ 1-2, 2003, págs. 134-135. 
política monetaria se caracteriza por una intervención disciplinaria dirigida a la preservación del modelo de constitución económica de los Tratados. En particular, en la dirección económica de la Unión los preceptos claves se sitúan en el ya mencionado artículo 119 del TFUE, y en el artículo 120 del TFUE. De la lectura conjunta de ambas disposiciones se deriva que la Unión no tiene libertad en la definición de su política económica, sobre todo porque ésta ha de realizarse de acuerdo con el principio de economía abierta y de libre competencia (artículo 120), y los principios de precios estables, finanzas públicas y condiciones monetarias sólidas y balanza de pagos estable (artículo 119.3). Un contenido que limita la capacidad de dirección económica de las orientaciones generales de la política económica. Su función no es condicionar el mercado, sino controlar el comportamiento de los Estados con respecto a las condiciones de sanidad del sistema mencionadas. Esta debilidad de la política económica contrasta con la fortaleza de la política monetaria que materializa el momento de control como tutela-garantía de la autonomía del mercado. El instrumento fundamental para su actuación aparece recogido en el artículo 126 del TFUE, la estabilidad presupuestaria. El efecto de la disciplina presupuestaria es que actúa como límite de los tradicionales instrumentos intervencionistas estatales en materia económica, fundamentalmente el gasto social, actuando como factor de erosión del vínculo social ${ }^{47}$

Al mismo tiempo, el alcance constitucional de todas las disposiciones fundamentales que conforman el gobierno de la moneda única pone de relieve que el objetivo de la estabilidad de precios y el derecho-deber de la independencia de las instituciones monetarias tanto a nivel nacional como europeo, son objetivos y requisitos fundamentales en la consolidación y en el avance del proceso de integración europea ${ }^{48}$.

También con relación a los objetivos de política económica, el artículo 126 del TFUE reproduce literalmente el texto del antiguo artículo 104 del TCE. Desde esta perspectiva se ha destacado que «la constitución económica europea condiciona el atípico proceso constituyente europeo, determinando su contenido. Los contenidos relativos a la tutela y la preeminencia del mercado, a las condiciones sanitarias de su funcionamiento y a la primacía de las reglas técnicas en contraposición a la lógica política en la intervención, continúan inmutables» ${ }^{49}$.

${ }^{47}$ Maestro Buelga, G., «El vínculo presupuestario comunitario y los derechos sociales», Revista Vasca de Administración Pública, n. ${ }^{\circ}$ 64, 2002, pp. 201-207

${ }^{48}$ Miccú, R., «Finalismo dell’Unione ed economia sociale di mercato: modello (obsoleto) o 'principio di speranza' del costituzionalismo europeo»»», op.cit., pp. 149-150.

49 Maestro Buelga, G., «Estado de mercado y constitución económica: algunas reflexiones sobre la crisis constitucional europea», Revista de Derecho Constitucional Europeo, n. ${ }^{\circ} 8,2007$, p. 64. 
Por ello, en el Tratado de Lisboa la tensión entre autonomía del mercado e intervención condicionadora sobre éste, se resuelve claramente a favor del mercado que permanece ajeno a cualquier condicionante normativo. Sólo resta añadir que después del debate de la Convención, el modelo de constitución económica no superó la formulación de los artículos 2, 3 y 4 del TCE (actual artículo 3 del TUE, y artículo 119 TFUE), manteniéndose la configuración del modelo en los términos descritos.

De tal forma que la expresión del artículo 3.3 del TUE «economía social de mercado altamente competitiva», dista de representar un avance en el proceso de incorporación a la constitución económica europea de previsiones dirigidas a reequilibrar las relaciones entre la integración económica y la integración social. Más bien, ésta se articula en torno al paradigma de la «economía de mercado abierta y de libre competencia» como modelo económico del constitucionalismo de mercado europeo que determina los espacios para su realización. Por eso, la vinculación de la economía social de mercado al constitucionalismo social y económico de la forma de Estado social es, cuanto menos, cuestionable.

La articulación de las relaciones política-economía que se establecen desde la economía social de mercado altamente competitiva, difiere de las del modelo constitucional gestado a finales de la segunda guerra mundial en el que se establecía un equilibrio entre las dimensiones social y económica. Frente a la constitucionalización del Estado social, el proyecto europeo se vincula desde sus orígenes a las propuestas de la Escuela de Friburgo. De ahí la interpretación de que la constitución económica de la CEE fuera el refugio de la corriente ordoliberal frente a la deriva social-interventora del constitucionalismo del Estado social en la posguerra ${ }^{50}$; es más, la economía social de mercado pertenece a esta tradición y recupera la propuesta original ${ }^{51}$.

En la propuesta ordoliberal la constitución económica se presenta como opuesta a la constitución económica del constitucionalismo social. Se trata de una regulación indirecta y no de una dirección estatal del sistema económico. De hecho, en la regulación indirecta el poder político establece las condiciones estructurales para el funcionamiento efectivo del proceso, siendo el vínculo económico el que define los límites de la esfera pública en el mercado, y el derecho de la competencia como garantía de la competencia regulada el que rige su funcionamiento.

En este núcleo político económico, la competencia actúa con un carácter constructivo dirigido a restituir su papel como fuerza estimuladora y medio de organización social a través de acciones dirigidas a conservar y a esta-

${ }^{50}$ Joerges, Chr., «Que reste -t-il de la Constitution économique européenne aprés la constitutionalisation de l'Europe - Une rétrospective mélancolique», en Cahiers Européens de Science, n. ${ }^{\circ} 1,2005$, pp. 15-19.

51 Joerges, Chr \& Rödl, F., «Social market economy as Europe's social model?», EUI WP LAW, n. ${ }^{\circ}$ 8, 2004, pp. 19-20. 
bilizar la eficiencia económica de la competencia. Precisamente, para los teóricos del ordoliberalismo el objetivo de la "Vollständiger Wettbewerb», traducido como "competencia perfecta», constituye la esencia del orden económico, haciendo de ella el principio guía de la política gubernamental ${ }^{52}$.

La teorización que se efectúa de la competencia materializa el abandono tanto del postulado liberal del no intervencionismo, como del postulado social del intervencionismo corrector de las desigualdades socio-económicas que genera el mercado. Con respecto al paradigma liberal, porque la garantía de la competencia perfecta se convierte en el problema fundamental para el que el poder público es a su vez, un mecanismo indispensable. La existencia de una economía con libre competencia es garantizada por el Estado que ejerce un papel constitutivo en el orden de mercado que deja de ser espontáneo.

La división de espacios público y privado desaparece en el marco de la propuesta ordoliberal. Con respecto al constitucionalismo social, porque la competencia además de actuar como mecanismo legitimador de la intervención estatal, lo hace como límite a una mayor intervención del Estado en la economía, dado que «la legitimidad de la intervención estatal es la garantía de la competencia, que es la garantía del mercado libre ${ }^{53}$. El Estado sólo interviene cuando las condiciones del mercado ponen en peligro la competencia que es la que define el espacio de poder político y su ámbito de realización. Desde esta perspectiva, se produce una funcionalización de la política que invierte la relación entre economía y política forjada en el Estado social.

Resta por referirse al segundo de los elementos significativos del pensamiento ordoliberal en cuanto a su incidencia en el ordenamiento europeo, especialmente, tras su introducción formal en el Tratado de Lisboa. La apertura al intervencionismo estatal permite una ampliación del espacio público que se extiende a la política social y a la intervención sobre la coyuntura. La «economía social de mercado» en las formulaciones de Friburgo se considera sin embargo, siempre subordinada a la lógica del mercado, encontrando sus límites en la preservación de éste último.

Así, aunque la economía social de mercado se basa en una competencia constructiva desarrollada en el terreno de la calidad y la eficiencia que exige la conexión con campos de acción limítrofe a la economía como son el de la acción social, el fomento del objetivo social de la economía social de mercado actúa de una manera consustancial con los principios del mercado. De hecho, entre los fines sociales figura la protección de la competencia. También la política económica activa debe limitarse a adoptar medidas orientadas

${ }^{52}$ BöHM, F., Die Ordnung der Wirtschaft als geschiftliche Aufgabe und rechtsschöpferische Leistung, Stuttgart, 1936.

53 Garcia Herrera, M. A \& Maestro Buelga, G., «Dirección económica y mercado en la Constitución europea», Cuestiones Constitucionales, n. ${ }^{\circ} 15.2006$, p. 144. 
al mercado y definidas como «medidas que aseguran la finalidad social sin deteriorar ni entorpecer el mecanismo del mercado» ${ }^{54}$.

Por eso, en la economía social de mercado todas las políticas sociales están subordinadas a la lógica del mercado en la que tienen sus límites. Lo decisivo en la política social es la renuncia a intentar llevar a cabo reformas sociales mediante intervenciones que alteren el equilibrio del mercado. Se trata de sustituir las manipulaciones directas por una política social indirecta que en modo alguno pueda originar un bloqueo del mercado económico y, en última instancia, la renuncia a toda política social que no sea conforme al mercado ${ }^{55}$.

Esta remercantilización del vínculo social es especialmente visible en la política de empleo de la Unión. De hecho, las políticas económicas y monetarias aparecen como el marco de definición de la política de empleo europea. El dispositivo con el que cuenta la UE para la dirección de la política económica son las orientaciones generales de las políticas económicas de los Estados miembros y de la Unión (OGPE), y de forma subordinada, la coordinación de las políticas de empleo. La legitimidad de ambos instrumentos se establece en el artículo 119 del TFUE «estrecha coordinación de las políticas económicas de los Estados miembros». Competencialmente, esta legitimidad se especifica en los artículos 120 y 121 del TFUE, para la política económica, y 145 y 146 del TFUE, para la política de empleo. Si bien la panoplia instrumental en política económica puede ser en un primer momento confusa, lo cierto es que la intervención económica y la del empleo carecen de la misma relevancia en el gobierno económico europeo.

La coordinación de las actuaciones de los Estados miembros en materia de empleo tiene lugar en el seno del Consejo (artículo 146.2 del TFUE). Además, el peso de la intergubernamentalidad se acentúa con respecto a las OGPE en las que la dirección comunitaria si está claramente formulada, y desde el punto de vista competencial, se configura como una función de indirizzo general cuyo punto de partida es la Comisión y su configuración formal corresponde al Consejo (artículo 121. 2 del TFUE). Al mismo tiempo, los mecanismos de control se atenúan, «informe conjunto anual elaborado por la Comisión y el Consejo» (artículo 148.1 del TFUE). Desde esta perspectiva, su posible vinculación a los Estados miembros se relativiza comprometiendo la función de dirección que pudieran cumplir, lo que impide el reconocimiento de una política de empleo europea.

Cuestión que no es de extrañar si se tiene en cuenta la preeminencia de los objetivos económicos que sitúan a la política de empleo en una posición subalterna, limitando su capacidad de influir en la política económica. In-

${ }^{54}$ MÜller-Armack, A., Soziale Markwirtschaft und Europäische Wirtschaftsgemeinschaf», Wirtschaftsordnung und Wirtschaftspolitik, Haupt, Stuttgart, 1976, p. 243.

55 Müller-Armack, A., Soziale Markwirtschaft und Europäische Wirtschaftsgemeinschaft, op.cit., pp. 244-245. 
virtiendo de esta manera la relación que caracteriza a estos espacios en el Estado social. Por una parte, la política de empleo tiene que ser compatible con las orientaciones generales de las políticas económicas de los Estados miembros y de la Unión (artículo 146.1 del TFUE)), siendo el principio fundamental la estabilidad macroeconómica que desempeña funciones de dirección negativa. Por otra, la ausencia de sanciones ante una eventual inobservancia de estas orientaciones en materia de empleo, contrasta con el sistema de medidas que si se prevén en materia de déficit público excesivo (artículo 126.11 del TFUE). Por último, la formulación del fomento del empleo no como objetivo, sino como un «asunto de interés común», expresión con una más que considerable densidad normativa, imposibilita su reconducción a un reconocimiento del trabajo en sentido político-jurídico.

El objetivo «tendente al pleno empleo» formulado por el artículo 3.3 del TUE, y a cuyo logro contribuirán las políticas de empleo de los Estados miembros, implica la adopción de mecanismos compatibles con los parámetros de la constitución económica europea. Y donde los nuevos factores de la capacitación y la flexiguridad asumen la centralidad reservada en la constitución económica del Estado social a las políticas intervencionistas del pleno empleo, en los términos de potenciar una mano de obra cualificada, formada y adaptable y mercados laborales con capacidad de respuesta al cambio económico (artículo 145 del TFUE).

Desde esta óptica, los intentos por reequilibrar los contenidos de la constitución económica europea, estabilidad monetaria y equilibrio macroeconómico, con la promoción de una economía social de mercado altamente competitiva, tendente al pleno empleo y al progreso social, son baldíos. Fundamentalmente, porque es el principio organizativo de conformidad con el mercado interior, el que determina la debilidad y subalternidad de la dimensión macroeconómica de las políticas de empleo.

Estas referencias contribuyen a poner de relieve la funcionalidad de la intervención pública ordoliberal al mercado y a la garantía de su funcionamiento, así como también la subordinación de la política social al mercado a través de su compatibilidad subalterna.

\subsection{La justicia social competitiva.}

Con relación a la dimensión social del constitucionalismo de mercado europeo, está condicionada por los principios fundamentales del nuevo modelo: el mercado y la competencia. La determinación del nivel apropiado de intervención pública en el mercado se desplaza al propio mercado como espacio de actuación y promoción de la competencia interterritorial. Es el diseño político-económico europeo de la economía de mercado abierta y de libre competencia como mecanismo desregulador de los vínculos políticos del Estado social y garante institucional de los mecanismos de mercado.

La ausencia de mecanismos jurídicos vinculados a las tradiciones del constitucionalismo social en el espacio transnacional que ofrezcan una res- 
puesta a la demanda de la distribución, traslada al ámbito social la competencia interterritorial en el seno de la Unión Europea. La competencia define el espacio de intervención que ahora es el mercado, es decir, la competencia como decisión constitucional no sólo se limita a configurar el ámbito de protección del mercado contra las tendencias a la concentración económica que pudieran distorsionar su efectiva realización, sino que se articula como espacio del intervencionismo económico del constitucionalismo de mercado frente a la intervención económica del Estado social ${ }^{56}$.

Al mismo tiempo, la competencia actúa redefiniendo la justicia social que ahora es una justicia social competitiva desde una doble perspectiva. La justicia social se convierte en un coste externo que graba al mercado dificultando la maximización de la competencia e invirtiendo el carácter de la intervención social de la constitución económica del Estado social. Para evitarlo, la justicia social deja de ser un concepto ajeno a los requerimientos del mercado para encontrar en éste el espacio para su actuación. La colonización mercantilista de la justicia social conlleva una retirada de los vínculos sociales en la construcción del nuevo paradigma ${ }^{57}$.

La despublificación de la justicia social supone la consolidación del mercado interior como referente primario determinante del nuevo contenido de la justicia social, en el que la protección y las políticas de tipo distributivo ceden paso al logro del éxito competitivo y productivo que se convierten en los mecanismos de defensa de la justicia social nacional. Pero además, la búsqueda y persecución de mejoras en el ámbito productivo y en términos de competitividad, se realiza utilizando la política en el interior y con el mercado, corroborando la vinculación de la mejora de las condiciones de bienestar social a la construcción del mercado formulada en los Tratados originarios.

El contenido de la justicia social no es la redistribución porque redistribuir significa corregir la actuación del mercado, y por lo tanto, actuar sobre la competencia. Por eso, el activo social de la sistemática de la Unión Europea se configura desde la institución del mercado interior, principal motor del proceso de integración. En el proyecto europeo definido conforme a una «economía social de mercado altamente competitiva», la ausencia de una política social europea desvinculada del mercado se justifica no en las reservas a la autonomía social de los gobiernos nacionales, sino en el condicionante de su conformidad con el mercado ${ }^{58}$.

De tal manera que la intervención social de las instituciones europeas es legítima si está justificada por las exigencias del modelo de justicia social

${ }^{56}$ Maestro Buelga, G., «El impacto de la ampliación de la U.E. sobre el modelo social europeo», Revista de Derecho comunitario europeo, n. ${ }^{\circ} 23,2006$, pp. 29-30.

${ }_{57}$ Maestro Buelga. G. «El impacto de la ampliación de la U.E. sobre el modelo social europeo», Revista de Derecho comunitario europeo, op.cit., pp. 29-30.

58 Barcellona, P., «Crisi dello Stato sociale e strategia dei diritti: un `hipotesi critica», Le ragioni del diritto. Scritti in onore di Luigi Mengoni, Giuffré, Milano, pp. 1697-1722. 
competitiva que determina el tránsito a un modelo social correspondiente al constitucionalismo de mercado europeo, en el que la subordinación de la política social a los imperativos del mercado interior y la libre competencia ilustran la ruptura del modelo, y la intrínseca potencialidad negativa del derecho de la competencia es una cuestión de coherencia con el nuevo modelo. La nueva justicia social se diferencia de la de tipo distributivo orientada a la corrección del mercado que actuaba en el Estado social. En ésta la competencia se configura como el ámbito de actuación exclusivo y excluyente de la intervención social. Sin embargo, no se trata de actuar sobre la competencia, sino de mejorarla a través del aumento de las condiciones de competencia nacionales en el mercado interior económico constitucionalizado, autonomía de mercado y libre competencia.

Unas reflexiones que se confirman a través del análisis del estado de la integración positiva en el Tratado de Lisboa.

\subsection{El modelo social europeo.}

Tomando como referencia los contenidos del ya citado artículo 3.3 del TUE, se pueden efectuar las siguientes consideraciones. En primer lugar, en el Tratado de Lisboa, el mercado interior abandona su conexión con la creación de un espacio de libertad, seguridad y justicia, para situarse junto con los objetivos sociales ya descritos. La cuestión que suscita su inclusión es si ésta supone que en el Tratado de Lisboa «no hay únicamente una mayor ligazón y cohesión entre los objetivos económicos y sociales y su compatibilidad debe ser más evidente, sino que además se visualiza, con más retórica, la voluntad de profundizar en la dimensión social del proceso de integración europea $\rangle^{59}$; o si por el contrario, el Tratado de Lisboa no hace sino profundizar en la preeminencia de la integración negativa reforzándola a través de la inclusión del paradigma del mercado interior como referente en el que el dispositivo social encuentra sus límites.

A tal fin resulta clarificadora la relación entre fines y medios, porque los medios determinan a los objetivos de la Unión en una relación extraña al constitucionalismo democrático. Los objetivos establecidos en el artículo 3.3 tienen un condicionamiento fundamental, se deben de realizar mediante el mercado interior y la UEM, así como las previsiones del «Protocolo sobre mercado interior y competencia». Concretamente, de acuerdo con el citado Protocolo, «el mercado interior tal y como se define en el artículo 3 del Tratado de la Unión Europea incluye un sistema que garantiza que no se falsea la competencia».

Por ello, el artículo 3.3 debe ponerse en contacto con las disposiciones que reproducen las políticas definidas en el artículo 119 del TFUE, reafir-

${ }^{59}$ En este sentido: Olesti Rayo, A., «La dimensión social del Tratado de Lisboa», en Martín y Pérez de Nanclares, J, (Coord), El Tratado de Lisboa: la salida de la crisis constitucional, Iustel, Madrid, 2008, p. 587. 
mando la reconducción del modelo a la 'economía de mercado y de libre competencia'. De tal forma que los medios vinculados a los principios del mercado y de la UEM, determinan el alcance de los fines de la Unión. Los objetivos sociales que se contemplan sólo pueden materializarse a través de su subordinación a las exigencias del mercado. El mercado interior y la libre competencia aparecen de nuevo como la decisión de principio del sistema que condiciona y preside el ordenamiento jurídico europeo, tal y como determinan los medios. Implican una jerarquización de los objetivos del artículo 3 del TUE, que confirma la continuidad del modelo de constitución económica respecto a los Tratados anteriores.

Desde estos parámetros deben interpretarse formulaciones como «la economía social de mercado altamente competitiva», que lejos de suponer una socialización de los objetivos de la UE, tienen en la tutela y garantía del mercado y las condiciones para su funcionamiento, su verdadera materialización normativa. La lógica del modelo desnaturaliza la expresión limitándola a la apertura de espacios de intervención subordinados a la preeminencia del mercado. Tal y como ya estableciera en su informe definitivo el Grupo IV 'Gobernanza Económica', la apostilla «altamente competitiva» privaba a la economía social de mercado de esa pretendida conexión con el modelo social europeo, situándola en el contexto de la constitución económica de los Tratados.

En segundo lugar, se debe tener en cuenta la omisión de toda referencia al modelo social europeo tanto en relación con los objetivos sociales, como con la caracterización de la dimensión social del proceso de integración europeo y los valores sobre los que se fundamenta la Unión. Frente a las demandas del Grupo XI «Europa Social» para que la definición de los objetivos de la Unión contuviera una referencia al modelo social europeo, las dificultades para la definición y funciones que cumple este modelo condujeron a los miembros del Grupo «Europa Social» a tomar como referentes a documentos políticos como las conclusiones de la Presidencia de Barcelona o la Estrategia de Lisboa, en los que el contenido del modelo social europeo se aborda en términos de «buenos resultados económicos, la competitividad, un alto nivel de protección social y educación y el diálogo social», o bajo el rótulo de la «Modernización».

Con respeto a la agenda de Lisboa, la modernización, de acuerdo con las propias formulaciones del Consejo, significa reforma de los sistemas de bienestar nacionales en la lógica de construcción de un «Estado activo de bienestar». Estableciendo una contraposición entre competitividad económica y los modelos de protección social herederos de la tradición del Estado Social, en la que la competitividad económica tiene una posición preferente. En las sucesivas manifestaciones de las instituciones comunitarias como es el Consejo de Barcelona, esta centralidad del mercado en la definición del modelo social europeo no hace sino confirmarse, porque el modelo social 
europeo expresa la subordinación de la política social a las exigencias del mercado y la competitividad económica.

Por lo tanto, este modelo no es el gestado en el Estado social, sino el que sanciona la primacía del mercado. El análisis de las políticas sociales y de empleo de la Unión, permite confirmar los caracteres de la naturaleza del modelo social del constitucionalismo de mercado europeo. De hecho, tal y como ponían de relieve las conclusiones de la Presidencia del Consejo de Niza de 2000 (apartado 12), la dimensión normativa del modelo social europeo, «se ha desarrollado a lo largo de los últimos cuarenta años a través de un acervo comunitario sustancial que los Tratados de Maastricht a Ámsterdam han permitido reforzar considerablemente, junto a normas de derecho derivado referidas a la libre circulación de trabajadores, la igualdad de género en el ámbito laboral, salud y condiciones de trabajo de los trabajadores...». Mencionándose también los capítulos sociales de los Tratados $\mathrm{y}$, en especial, el del empleo introducido por Ámsterdam. A este respecto podemos señalar que el Título IX del TFUE, reproduce los contenidos del Título VIII de Ámsterdam. En el Tratado de Lisboa, el pleno empleo no figura entre los objetivos del artículo 3.3 del TUE. La expresión «tendente al pleno empleo» lo aleja de los enunciados constitucionales de la posguerra. Tampoco las disposiciones del Título IX son capaces de introducir contenidos significativos que corrijan la fuerte asimetría entre integración negativa e integración positiva.

Con relación a la política social, de acuerdo con el apartado segundo del artículo 151 TUE, la política social deberá de hacer las cuentas con la necesidad de salvaguardar la competitividad de la economía europea. Además, el párrafo tercero de la disposición establece que los distintos objetivos sociales contemplados por la norma serán obtenidos en primer lugar, por el funcionamiento del mercado interior que favorecerá a su vez, la armonización de los sistemas sociales. De esta manera, la política social está sometida a un balance desigual con las exigencias monetarias de eficiencia económica y estabilidad presupuestaria en las que el medio para su realización, unas finanzas públicas saneadas, no sólo está en un nivel jerárquico superior al fin social, sino que además, determina su alcance jurídico real.

En tercer lugar, la Carta de Derechos Fundamentales de la Unión Europea (CDFUE) se incluye en el artículo 6.1 del TUE. «La Unión reconoce los derechos, libertades y principios enunciados en la Carta de los Derechos Fundamentales de la Unión Europea del 7 de diciembre de 2007 en Estrasburgo, la cual tendrá el mismo valor jurídico que los Tratados». Aunque a diferencia del malogrado Tratado Constitucional, la CDFUE no se integra en sentido físico, sino que se incorpora al ordenamiento jurídico europeo a través de una técnica jurídica de remisión que la desconstitucionaliza del sistema de los Tratados. Esto supone que aun atribuyéndole un valor igual al del TUE y el TFUE, la Carta de Derechos abandona el limbo de la región 
vaporosa de las declaraciones solemnes, se trata de una «normatividad comunitaria» ${ }^{60}$ atenuada o debilitada.

Además, la remisión a la misma tal y como fue adoptada el 7 de diciembre de 2007, implica que la versión de referencia es la del documento normativo que fue incorporado al proyecto de Constitución Europea, es decir, la CDFUE de diciembre de 2000, en el que en las disposiciones generales que determinan el alcance y los límites de los derechos del texto de Niza, tienen un papel determinante los valores del mercado que terminan por desnaturalizar a los derechos sociales subordinándolos al vínculo económico.

Concretamente, el principio de indivisibilidad, considerado como una de las aportaciones más significativas de la CDFUE, está comprometido a tenor de la distinción entre derechos y principios que establece el artículo 51.1. Se trata de una fórmula un tanto farragosa que la propia sistemática de la Carta no ayuda a aclarar. Por un lado, las instituciones y órganos de la Unión, así como los Estados miembros, únicamente cuando apliquen el Derecho de la Unión, respetarán los derechos, y cualquier limitación en su ejercicio y en el de las libertades deberá establecerse por ley y respetar en todo caso el contenido esencial del derecho (artículo 52.1). Como puede observarse, a diferencia de las libertades y los derechos, los principios no imponen a la UE y a los Estados la obligación de preservar su contenido esencial (del que dado el silencio de la Carta al respecto, a priori carecen), sino de observarlos y promover su aplicación con arreglo a sus respectivas competencias.

Analizando la redacción de ambos preceptos, el artículo 51 en combinación con lo dispuesto en el apartado primero del artículo 52, se puede llegar a la conclusión de que ambas categorías (los derechos y las libertades, de una parte, y los principios, de otra), obedecen al menos a una naturaleza jurídica diversa. La Carta contendría por un lado, derechos fundamentales en el sentido estricto del término, y otros que sólo empleando una noción más amplia de la expresión pueden ser calificados como tales ${ }^{61}$.

El texto no identifica a esos otros derechos que deben de ser calificados como principios, sino que generaliza la noción de derechos fundamentales en un intento de preservar el objetivo de la indivisibilidad de los derechos que el propio texto proclama. No obstante, son precisamente los derechos inspirados en el valor de la solidaridad los que se configuran propiamente como objetivos de política social y principios sociales.

En todo caso, la cuestión de fondo sobre los principios sociales es el amplio margen de discrecionalidad que establecen los límites previstos en el artículo 52. Determinar cuál es el grado de disponibilidad legislativa en la realización de los principios con un contenido prestacional, y cuál es la

${ }^{60}$ Expresión empleada por Monereo Pérez, J. L., La protección de los derechos fundamentales. El modelo europeo, Bomarzo, Albacete, 2009, p. 170.

${ }^{61}$ Rubio Llorente, F., «Mostrar los derechos sin destruir la Unión», Revista española de Derecho Constitucional, n. ${ }^{\circ}$ 64, 2002, pp. 36-40. 
competencia que la vía jurisdiccional tiene en esta materia, son los interrogantes más importantes que suscita el texto. Con respecto al papel activo o activismo judicial, teniendo en cuenta que «pasar por alto la evolución de la jurisprudencia de los Tribunales nacionales y todavía más del europeo, que han basado su propia identidad en torno al abandono de la consideración pasiva en los enfrentamientos con el legislador $\rangle^{62}$, está probablemente destinado a revelarse como ineficaz.

Las omisiones legislativas bendecidas por las jurisprudencias constitucionales nacionales estarían conectadas a las transformaciones de las garantías ofrecidas por el Estado Social y a la sostenibilidad financiera de los sistemas de bienestar que son a su vez, el reflejo de los postulados de la nueva constitución económica europea. Si la disciplina europea persigue la supremacía económica que condiciona la evolución de los derechos sociales, el planteamiento constitucional nacional aun no reconociendo formalmente dicha primacía, ha terminado por conceder una preeminencia al interés económico fiscal y de balance cuando emerge un preciso conflicto de intereses de acuerdo con un juicio de valor y legitimidad efectuado por los jueces constitucionales $^{63}$. Esta reducción de los derechos sociales a un juicio económico, ofrece un panorama desolador que se aleja de aquella imagen idílica de la creatividad jurisprudencial que parecía ofrecer el pluralismo jurídico de la Constitución por valores formalizado por la CDFUE ${ }^{64}$.

La segunda de las cuestiones referente a los límites establecidos para el legislador nacional y europeo, nos acerca a la segunda de las disposiciones generales de la Carta, el artículo 52. Los límites de los derechos determinan los márgenes de actuación de la praxis legislativa y, de esta manera, el grado de discrecionalidad del que se dispone. Se trata de una fórmula ambigua pero, en lo que atañe a los derechos sociales, la configuración de los objetivos de interés general como límites a los derechos condiciona su potencial alcance ${ }^{65}$. Nótese como se trata de una amplia noción que incluye además de los intereses protegidos por los artículos 36 del TFUE (donde se formaliza a través de la fórmula de la prohibición entre los Estados miembros de res-

${ }^{62}$ Colapietro, C., La giurisprudenza costituzionale nella crisi dello Stato Sociale, Cedam, Padova, 1996.

${ }^{63}$ Grandi, B., «Diritti sociali e allargamento de la UE: le problematiche conesse all'estensione dei diritti» Rivista del Diritto della Sicurezza Sociale, n. ${ }^{\circ}$ 3, 2005, p. 585.

${ }^{64}$ Un juicio positivo sobre las virtualidades de una interpretación por principios generales que avala la CDFUE en cuanto que se trata de disposiciones que poseen un mayor contenido axiológico y que permiten por lo tanto, un tipo de aplicación más amplio, puede verse en: Micheletti, M., «Carta dei diritti fondamentali dell'Unione Europea. Interpretazione per principi generali e pluralismo giuridico», Diritti Comunitario e degli Scambi Internazionali, n. ${ }^{\circ}$ 2, 2003, pp. 281-303.

${ }^{65}$ Ballestrero, M. V., «La Costituzionalizzazione dei diritti sociali», en S. ScArponi (a cura di), Globalizzazione e Diritto del Lavoro, Giuffré, Milano, 2001, pp. 99-100. 
tricciones cuantitativas a la importación y medidas de efecto equivalente, el principio de mutuo reconocimiento), y el artículo 45.3 del TFUE (donde se contempla la libre circulación de los trabajadores), los objetivos enumerados en el artículo 3.3 del TUE, de entre los que la competitividad se erige como el valor de los valores. De forma que la preservación del mercado interior es determinante del contenido y alcance de las disposiciones sociales de la CDFUE.

Por otro lado, según el apartado segundo del artículo 52: «los derechos reconocidos por la presente Carta que constituyen disposiciones de los Tratados se ejercerán en las condiciones y dentro de los límites determinados por estos». Los derechos sociales están formulados en el derecho originario bien como derechos accesorios a la libre circulación de trabajadores (artículos 45-48 TFUE), y por lo tanto, garantizados sólo en cuanto útiles para su pleno disfrute; o bien reconducidos a las políticas de empleo (artículos 145-150 TFUE) y las políticas sociales (artículos 151-161 TFUE), respectivamente. Con respecto a las disposiciones del Título IX del TFUE, Empleo, tal y como aparecen formuladas, ni siquiera es posible su reconducción a objetivo de la Unión (artículo 146 in fine). Por otra parte, la generalidad de las previsiones del Título X del TFUE, Política social, impide articular o deducir derechos subjetivos accionables ante la jurisdicción competente.

Del tenor de estas disposiciones se desprende la funcionalidad de los principios sociales al área mercantil europea. Además, su reconducción en los Tratados al ámbito de las políticas europeas o a lo sumo, a una categoría intermedia como es la de derechos accesorios ${ }^{66}$, junto con los amplios márgenes de que dispone el legislador estatal y europeo en la determinación del contenido de los derechos, confirma que los derechos sociales en la Unión Europea se sitúan desde el punto de vista de su naturaleza jurídica, por debajo del valor jurídico con el que tales derechos eran configurados en la experiencia del constitucionalismo social, evidenciando una regresión que debilita su dinámica garantista. Conclusiones que se refuerzan si se efectúa un análisis pormenorizado de algunos de los derechos sociales contemplados por la Carta descendiendo al nivel del articulado ${ }^{67}$.

De ahí que a la consideración del carácter de fundamentales como una característica estructural de los derechos sociales para hacerles salir del estado residual al que los confinaba el espacio económico europeo, le corresponde la utilización de fórmulas jurídicas ambiguas que ponen de relieve la contraposición ya señalada entre la constitución económica europea y la del constitucionalismo social, como ámbito en el que se inscriben los derechos

${ }^{66}$ Bronzini, G., «I diritti sociali nella Costituzione Europea», Democrazia e Diritto, n. ${ }^{\circ}$ 1. 2000, p. 102. También del mismo autor: «La Costituzione Europea e i diritti sociali», Rivista Critica del Diritto del Lavoro, 2000, pp. 635-643, y, en especial, p. 639.

${ }^{67}$ Lasa López, A., Constitución económica y derecho al trabajo en la Unión Europea, Comares, Granada, 2011, pp. 140-154. 
sociales del Estado social. La identificación de la constitución económica europea con el mercado y los valores de los que es portador supone situar al documento de Niza en esta decisión de sistema a la que está vinculada, $\mathrm{y}$, por lo tanto, vincular su significado al complejo normativo tendente a la integración económica, lo que nos aporta una visión de conjunto ${ }^{68}$.

4.5. El papel de los principios fundamentales del ordenamiento europeolibertades económicas y competencia- en las decisiones del juez europeo.

Teniendo en cuenta las conclusiones alcanzadas al hilo del estudio del derecho positivo, es necesario abordar ahora la dimensión otorgada por el desarrollo jurisprudencial a los principios fundamentales del ordenamiento jurídico europeo, a fin de verificar si la vía jurisprudencial coadyuva a su afirmación a través de la aplicación de los postulados que los dotan de sentido.

En esta perspectiva podemos señalar que las libertades económicas y las disposiciones relativas a la política de la competencia, se configuran como los pilares de la constitución del mercado, como calificativos del proyecto de integración económica. En la filosofía del Tratado de Lisboa que permeabiliza a los principios generales de la Unión, estos aparecen contextualizados y vinculados a la realización, formación y garantía de funcionamiento del mercado interior. La relación de complementariedad ${ }^{69}$ entre ambos tipos de disposiciones materializa su significado como condición sine qua non de las estructuras y dinámicas del mercado, lo que permite la progresiva afirmación hegemónica de la constitución económica europea.

$\mathrm{Su}$ vocación innata para adquirir un estatus superior al de las políticas sectoriales europeas conduce a su omnipresencia en todos los ámbitos de la economía: bien en términos directos, a través del establecimiento de comportamientos en régimen de competencia de los participantes en el mercado (con la eliminación de restricciones inherentes a la propia estructura del instituto del mercado- artículos 101 y 102 del TFUE, y de restricciones exógenas al mismo- artículo 106 del TFUE.); bien en términos indirectos, a través de las disposiciones que regulan la libre circulación de los factores de producción - artículos 28-29, 45-66 del TFUE.

En la génesis del proceso de integración europeo los obstáculos a las libertades económicas y los principios y políticas de la competencia han representado un campo privilegiado para el activismo jurisprudencial. El juez europeo partiendo del análisis de las políticas sectoriales establecía su vinculación con el funcionamiento del mercado, deduciendo de estas polí-

${ }^{68}$ Maestro Buelga, G., «Il costituzionalismo democratico sociale e la Carta dei diritti fondamentali dell’Unione Europea», Quaderni di Rassegna Sindacale, n. ${ }^{\circ}$ 1, 2004, pp. 122 y ss.

69 StuYck, J., «Libre circulation et concurrente: les deux pilliers du marché commun», Mélanges en hommage á Michael Waelbroeck, Vol. II, Bruylant, Bruxelles, 1999, p. 1479. 
ticas el interés global de la Comunidad al que debían someterse los intereses nacionales. Pero también se han configurado como un ámbito propicio para visualizar el carácter abierto de la sistemática de los Tratados en los que se recogen tales principios, y donde la garantía del mercado aparece como el ámbito institucional desde el que se definen las relaciones entre los diferentes niveles de gobierno. Es por eso que en la práctica, las fronteras entre los espacios normativos de actuación europeo y nacional se diluyen. Precisamente, este carácter abierto y pragmático de la estructura del derecho primario es lo que permite analizar con mayor claridad la construcción jurisprudencial del sistema.

Si como hemos reiterado, la dinámica del constitucionalismo de mercado europeo manifiesta su preferencia por la estrategia basada en el principio de una economía de mercado abierta y de libre competencia, frente a la del Estado social y su correlato del intervencionismo público en la economía, no es de extrañar que el juez europeo haya manifestado la preeminencia de las normas de funcionamiento del espacio económico integrado en detrimento del constitucionalismo social estatal.

El paradigma lo constituye el principio de mutuo reconocimiento ${ }^{70}$ elaborado en la sentencia Cassis de Dijon (As. C-120/78), y que entra en escena cuando el recurso al artículo 36 del Tratado de Roma (actual artículo 36 del TFUE), se convirtió en una práctica constante por los Estados miembros que encontraban en esta disposición una vía de escape a las exigencias de la libre circulación de mercancías, y a la posibilidad de desplegar mecanismos de dirección económica en sus respectivos mercados nacionales.

Los potenciales efectos virtuosos de la lectura del artículo 30 del TCEE (actual artículo 34 del TFUE), se desplegaban más allá de su funcionalidad a la integración de los mercados en los Estados miembros, constituyendo un mecanismo especialmente útil para la liberalización de aquellos sectores nacionales que los países miembros intentaban proteger del mercado libre ${ }^{71}$. La apertura al comercio intracomunitario a través de la aceptación por los Estados miembros del reconocimiento mutuo de los estándares, implicaba la introducción de los condicionamientos de la constitución económica europea en aquellos ámbitos en los que los derechos nacionales conservaban el derecho a efectuar excepciones a las libertades económicas conforme al artículo 36 del TCEE.

La competencia como decisión constitucional no sólo se limita a configurar el ámbito de protección del mercado contra las tendencias a la concen-

${ }^{70}$ Grassi, P., «Il principio del mutuo riconoscimento delle legislazioni nazionali nell diritto communitario», en S. MANGIAMELI (a cura di), L'ordinamento europeo. L'esercizio delle competenze, Giuffré, Milano, 2006, pp. 391-442.

71 Poiares Maduro, M., «Reforming the market or the state? Article 30 and the European constitution: economic freedom and political rights», European Law Journal, n. o 1,1997 , pp. 55-82. 
tración que pudieran falsearla, sino que también se articula como el espacio del intervencionismo del vínculo económico frente al intervencionismo del Estado social. Una configuración de la competencia desde la que se debe considerar la vía jurisprudencial de Cassis de Dijon. En esta tesitura, la maximización de la ratio de aplicación del artículo 30 del TCEE, terminaba por captar casi cualquier tipo de regulación de los Estados miembros que se veían obligados a justificar las elecciones sociales realizadas en la regulación del mercado, en la medida en que dicho precepto se aplicaba independientemente del objeto y la finalidad de la regulación ${ }^{72}$.

A propósito de los efectos esterilizadores de las regulaciones sociales nacionales derivados del principio de mutuo reconocimiento, la célebre Sunday Trading Saga ${ }^{73}$ inaugurada a finales de los años ochenta, representa uno de los ejemplos más significativos. Sobre todo, porque el procedimiento seguido por el juez europeo para construir su argumentación se basa en un control de constitucionalidad inmanente a la lógica propia del constitucionalismo de mercado europeo. En concreto, es el principio fundamental de la libre circulación de mercancías el criterio sobre el que han de ponderarse y valorarse los intereses en juego desde una doble dimensión: las excepciones a esta libertad han de perseguir un interés legítimo desde el punto de vista del derecho de la Unión (legitimidad de la excepción); y los efectos de la normativa en cuestión no han de exceder de lo estrictamente necesario para conseguir el objetivo perseguido (proporcionalidad de la excepción). De esta manera, el control del juez europeo compromete directamente las elecciones de política económica y social de los legisladores nacionales, en la medida en que estas elecciones tienen que ser compatibles con los objetivos generales que no son sino el mercado y su corolario, la libre competencia.

En el análisis de costes (económicos) y beneficios (sociales) se valoran además de las perdidas de eficiencia económica y de la reducción de espacios de libre mercado, todas aquellas medidas que siendo menos restrictivas garanticen la obtención de un beneficio neto mayor. De modo que la necesidad y no la oportunidad política del fin social, junto con la imposibilidad de aplicar una medida alternativa que tenga un impacto menor en los intercambios, son los requisitos de justificación de la actuación del legislador

${ }^{72}$ Matera Ricigliano, A., «La sentenza Cassis de Dijon, un nuovo indirizzo programmatico per la realizzazione definitiva del mercado comune», Diritto Comunitario e degli Scambi Internazionali, 1991, pp. 263 y ss.

${ }^{73}$ Sentencia del Tribunal de Justicia de la Unión Europea de 23 de noviembre de 1989, As. C-145/88, Torfaen Borough Council v. B \& Q plc. El objeto de la controversia era si el efecto derivado del uso y disfrute del derecho de descanso dominical, como es el propio cierre del ejercicio comercial, podía ser considerado de acuerdo con el criterio de medida de efecto equivalente, una restricción cuantitativa a las importaciones. 
nacional ${ }^{74}$. Esta persistente dinámica expansiva de la libertad fundamental que el artículo 30 garantizaba, se refuerza en la década de los noventa a través de la ampliación de su ámbito de aplicación a los obstáculos ocasionados por sujetos privados, hasta el punto de prevalecer con respecto a posiciones jurídicas subjetivas de conflicto colectivo garantizadas como tales por los ordenamientos nacionales ${ }^{75}$.

Este principio del mutuo reconocimiento como técnica que favorece la competencia y el establecimiento de relaciones interterritoriales de competencia en el seno de la Unión, encuentra también aplicación en materia de libre prestación de servicios. Precisamente, es en las decisiones del juez europeo a propósito de la delimitación del ámbito de aplicación de la libre prestación de servicios y la libre circulación de trabajadores, donde la maximización de la competencia cobra todo su significado. La reconducción de los trabajadores desplazados temporalmente al ámbito de actuación de la libre prestación de servicios y no al de la libre circulación de trabajadores, materializa la asimetría entre la integración negativa y la integración social en la Unión.

De acuerdo con la reciente jurisprudencia (SSTJUE, As.C-438/05 Viking, As.C-341/05 Laval, As. C-346/06, Rüffert) ${ }^{76}$ del Tribunal de Justicia de la Unión Europea (TJUE), las diferencias entre una y otra libertad estarían en los distintos objetivos llamados a realizar por ambas. Mientras que en la libre circulación de trabajadores la prohibición de discriminación se vincula a la integración del mercado interior europeo, en la libre prestación de servicios el fin perseguido es ante todo la liberalización de los sectores nacionales protegidos, incluidas las normas de derecho laboral nacional que pudieran incidir en la efectiva realización de la libre prestación de servicios. La maximización de la competencia desplaza a la prohibición de discriminación y se configura como el elemento clave de funcionamiento de esta libertad económica.

La libre prestación de servicios al estar dirigida a la realización de la libre competencia, que junto con la economía de mercado representan los

${ }^{74}$ Poiares Maduro, M., We the Court. The European Court of Justice and the European economic constitution, Oxford-Portland, Oregon, 1998, pp. 49-58.

75 Tal y como se desprende del Asunto Comisión c. República Francesa (C-265/95), en el que juez europeo no entró a valorar si las acciones acometidas por agricultores franceses eran o no constitutivas de una medida de conflicto colectivo, sino que simplemente las consideró como restricciones a la libre circulación de mercancías.

${ }^{76}$ En todos los asuntos el leit motiv es la aplicación del principio del país de origen en materia de condiciones laborales al personal dependiente de una empresa establecida en un Estado miembro, que se desplaza temporalmente para la prestación del servicio al territorio de otro Estado miembro. Condiciones laborales que se traducen en el bajo coste del trabajo como arma competitiva para ganar posiciones en el mercado con respecto a las empresas de los Estados miembros con legislaciones laborales más garantistas. 
contenidos en torno a los que se articula la decisión política fundamental del ordenamiento jurídico europeo, se erige como libertad fundamental con un estatus jerárquico superior al de la libre circulación de trabajadores. Interpretada la libre prestación de servicios como parámetro de desarrollo directo de uno de los valores constitucionales, el TJUE elude la prohibición de discriminación en base a la nacionalidad favoreciendo la configuración de lo social como espacio de competencia. La protección de la ventaja competitiva de los países con un menor coste social no es sino la protección del propio modelo social que se articula desde la instancia europea, la justicia social competitiva.

Finalmente, es el momento de hacer referencia al papel desempeñado por el TJUE, en cuanto a la valoración y alcance de la relación que se establece entre los derechos sociales y las libertades económicas. Partiendo de la maximización de una economía de mercado abierta y de libre competencia, algunos pronunciamientos jurisprudenciales han producido un incremento cuantitativo de derechos sociales a prestaciones financiadas por el Estado e inmediatamente accionables ${ }^{77}$. Sin embargo, esta tutela está en una posición instrumental con respecto a la de las libertades económicas que a su vez, son los pilares fundamentales para la realización del objetivo económico por excelencia, mercado interior en régimen de libre competencia, al que los Estados miembros deben concurrir para su realización. Este representa el núcleo intangible del constitucionalismo de mercado como expresión de la máxima inderogable y jerárquicamente absoluta.

En este contexto, el establecimiento de derechos con un contenido prestacional puede considerarse como un efecto meramente consecuencial de la actuación del principio de igualdad de tratamiento y de no discriminación que impregna a las libertades fundamentales. Se trata de derechos de comunicación desvinculados de cualquier aplicación de estándares unitarios. Respecto a la igualdad de tratamiento, no implica la creación de nuevos derechos sino la extensión de los ya existentes en los sistemas nacionales. De esta manera, no son derechos sociales reconocidos en el espacio europeo e impuestos a los Estados miembros, sino derechos de base estatal que en función de su conexión o reconducción a una de las libertades económicas, en este caso, la libre circulación que si forma parte del sistema de derechos de la UE, impone la necesaria comunicación entre los ordenamientos nacionales y el de la Unión. El contenido del derecho se define en el ámbito estatal. Además, se articula en un contexto donde los condicionamientos económicos están muy presentes. De hecho, la suficiencia económica constituye una

77 Sentencia del Tribunal de Justicia de la Unión Europea de 15 de enero de 1998, As. C-15/96, Schoning Kougebetopoulou. Para un análisis más detallado de la actuación jurisprudencial: Mondin, A., «Equilibrio finanziario e diritti sociali: dal Trattato CE alla Carta dei diritti fondamentali dell'Unione Europea», Rivista di Diritto Finanziario e Scienza delle Finanze, L XII, 2, 1, 2003, pp. 269 y ss. 
condición sine qua non para el ejercicio de la libertad de residencia, requisito que no ha sido revisado por la jurisprudencia del TJUE. Ilustran esta situación los asuntos D’Hoop (As. C-244/98) y Grzelecky (As. C-184/99), entre otros.

Con respecto a la conexión entre derechos sociales y el principio de no discriminación por razón de género, se trata de una perspectiva que tampoco a nuestro parecer puede constituirse como una fuente de derechos autónomos. En primer lugar, porque su fundamento es el de la igualdad formal y, por lo tanto, desvinculado de la igualdad sustancial propia de los derechos sociales que permite reconocer con claridad los valores de justicia social que deben de condicionar las elecciones del legislador. Además, se trata de un principio que por sí mismo no forma parte de la categoría de los derechos sociales.

En segundo lugar, porque en el diseño político institucional de la UE, el principio de igualdad se persigue utilizando el criterio exclusivo y excluyente de las formas de discriminación, tal y como se desprende de la formulación de la igualdad acogida por la CDFUE (artículo 20$)^{78}$.

Esta posición marginal de los derechos sociales en el discurso de los derechos fundamentales desarrollados por el TJUE, es coherente con el dato normativo europeo. Los objetivos económicos han sido traducidos en los Tratados en un principio jurídico general de libertad de iniciativa económica inmanente en las reglas específicas de los Tratados que sancionan las libertades de circulación, además de las libertades de establecimiento y la libre competencia. No sucede lo mismo con los contenidos sociales, respecto a los que la Unión Europea a través de normas con un contenido muy genérico y no detallado habría asumido un mero empeño político para mejorar los niveles de protección social, privados de efectividad jurídica en cuanto destinados a orientar genéricamente las políticas europeas en materia social.

El hecho de que solo recientemente y sobre la base del derecho derivado de la normativa europea el TJUE haya utilizado la expresión «derecho social $\gg^{79}$, es revelador de la situación descrita. Además, la trascendencia de esta decisión judicial ha de relativizarse, ya que es más consecuencia de una aplicación extensiva del derecho derivado (Directiva 93/104/CE, del Consejo, de 23 de noviembre de 1993, relativa a determinados aspectos del tiempo de trabajo) que de un giro jurisprudencial en materia de derechos sociales. De tal forma que ni los derechos sociales han entrado en el ámbito constitucional europeo, ni se ha materializado su entrada en los principios generales

${ }^{78}$ SAlmoni, F., «Diritti sociali fondamentali e Unione Europea. Dall’ordinamento comunitario allo Stato Sociale Europeo», en Studi in onore di Gianni Ferrara, AAVV, Vol. III, Giappichelli, Turín, 2005, pp. 551-554.

79 Sentencia del Tribunal de Justicia de la Unión Europea (Sala Sexta) de 26 de junio de 2001, As. C-173/99, Broadcasting, Entertainment, Cinematographic and Theatre Union (BECTU) c. The Queen y Secretary of State for Trade and Industry. 
del derecho como categoría jurídica que permitió asentar los derechos de tradición liberal en la jurisprudencia europea ${ }^{80}$.

A la vista de estas premisas puede decirse que la nueva constitución material que hemos identificado en la constitución económica europea, «sancionada en la reforma de Lisboa, no hace sino consolidar la asimetría entre integración negativa y positiva, confinando a ésta a la marginalidad en el modelo» ${ }^{81}$.

\section{CONSIDERACIONES FINALES.}

La constitución económica europea representa el principal espacio de transformación del constitucionalismo europeo compuesto, núcleo de la nueva constitución material que implica la ruptura de las bases materiales del Estado social. De ahí que la constitución económica europea como nueva constitución material se presente como el marco de resolución de la relación entre ordenamientos. Es desde la realidad material del mercado desde la que se construye el complejo jurídico constitucional e institucional europeo ${ }^{82}$. La integración de los mercados de los Estados miembros en un mercado interior europeo se realiza desde el nivel europeo y su construcción desde el mercado, en confrontación con el constitucionalismo social. En este sentido, la nueva constitución económica es el punto de partida para definir la nueva realidad constitucional y su constitución material. Ilustra la relación entre la constitución material y la fase de transición del actual momento constitucional como fase de aparición de la nueva relación Estado-sociedad que se establece ${ }^{83}$.

Lo fundamental es que la nueva constitución material realiza la ruptura de los vínculos sociales al sistema económico que se establecen en el constitucionalismo social. La definición de la intervención social por y desde el mercado determina una nueva centralidad que supone la contradicción entre mercado e integración del trabajo, estableciendo las bases de la nueva constitución económica ${ }^{84}$. La remercantilización del Estado sitúa en el centro de la forma de Estado al mercado, sancionando su autonomía y vinculando la

${ }^{80}$ Ridola, P., «Diritti di libertá e mercato nella Costituzione europea», Quaderni Costituzionali, n. ${ }^{\circ}$ 1, 2000, pp. 15 y ss. CARTABIA, M., Principi inviolabili e integrazione europea, Giuffré, Milano, 1995, p. 55. LuCIANI, M., «Diritti sociali e integrazione europea», Politica del Diritto, n. ${ }^{\circ}$ 3, 2000, pp. 376-377.

${ }^{81}$ Maestro Buelga, G., «El Tratado de Lisboa y la constitución económica», op.cit., p. 67.

${ }^{82}$ Bilancia, F., «Brevi note su Costituzione materiale, legalitá e Unione Europea», op. cit., pp. 429-432.

${ }^{83}$ Maestro Buelga, G., «Estado de mercado y constitución económica: algunas reflexiones sobre la crisis constitucional europea», op.cit., pp. 45-62.

${ }^{84}$ Barcellona, P., «Globalizzazione e crisi dello Stato Sociale», Contro Maastricht, Punto Rosso, Roma, 1997, pp. 82-101. 
actividad pública a la tutela-garantías de este último. Frente a la integración del trabajo, la integración del mercado implica la expulsión del trabajo como sujeto constitucional que pierde de esta manera su capacidad de configurarse como principio organizativo que reunifica en un sistema unitario al ordenamiento jurídico en su conjunto.

Ahora es el mercado el que realiza esta función, el que legitima la intervención pública en un modelo económico dirigido a la preservación del mercado y al fomento del impulso del capital. En la nueva relación, el capital emerge como la fuerza dominante del conflicto que despliega sus efectos en la constitución material de la nueva realidad constitucional. La compatibilidad entre mercado y garantía de integración del trabajo desaparece simplemente porque el trabajo pierde su capacidad de codeterminar el conflicto y su composición. Disuelta la constitución material del Estado social que contribuía a legitimar el doble compromiso de integración política y económica del trabajo, el capital se impone como el único sujeto capaz de definir autónomamente la nueva constitución material. La segmentación y disminución del trabajo como consecuencia de la fragmentación del movimiento obrero, le impide configurarse junto con el capital como sujeto definidor del conflicto $^{85}$.

En definitiva, la constitución económica del ordenamiento jurídico europeo actúa redefiniendo la constitución material de los Estados miembros. Como momento de ruptura que provoca una modificación en la forma sustancial de la constitución vinculada a la tradición del constitucionalismo social, presenta una contradicción entre constitución formal nacional y nueva constitución material resuelta normativamente a través de la armonización que desde el constitucionalismo compuesto realiza la constitución económica europea con el constitucionalismo estatal ${ }^{86}$.

TITLE: Methodological considerations on the new relationship between State, Law and Social Justice within the European market constitutionalism.

RESUMEN: Las novedades registradas en las últimas décadas en el ordenamiento europeo han introducido un escenario de reflexión con respecto al constitucionalismo del Estado social. Concretamente, la contradicción entre un constitucionalismo gestado en el proceso de construcción del Estado social y la nueva realidad constitucional que plantea la in-

${ }^{85}$ Orlandini, G., «Mortati e il lavoro che non c'é piú», en L. Gaeta (a cura di), Atti della Giornata di Studio. Siena, 31 gennaio 2003, Constantino Mortati e 'Il lavoro nella Costituzione': una rilettura, Giuffré, Milano, 2005, pp. 217-221.

${ }^{86}$ Maestro Buelga, G., «Constitución compuesta y relación ordinamental: a propósito del proyecto del Tratado Constitucional de la Convención Europea», en L. AGUIAR DE LuQue (Coord), Constitución, Estado de las Autonomías y Justicia Constitucional (Libro homenaje al profesor Gumersindo Trujillo), Tirant Lo Blanch, Valencia, 2005, pp. 201236. 
tegración europea. Este actual momento constitucional plantea la necesidad de buscar orientaciones metodológicas que ayuden a la comprensión de la confrontación descrita, y entre éstas destacan las que analizan la relación Unión Europea-Estados miembros desde la perspectiva de la crisis de la constitución material de las constituciones nacionales. De hecho, el progresivo desmantelamiento de las bases del Estado social ejemplificaría la confrontación Constitución del Estado social-realidad.

PALABRAS CLAVE: constitucionalismo social, constitución material, constitución económica europea.

ABSTRACT: In recent years the novelties included by the European legal system have introduced a scenario of reflection with regard to the Social state constitutionalism. That is, the contradiction between the social constitutionalism and the new European constitutional reality. This current constitutional moment poses the need to seek methodological guidelines for understanding the confrontation described, and among these guidelines highlight those that analyse the relationship European Union-Member States from the perspective of the crisis of the material constitution of national constitutions. In fact, the progressive dismantling of the basis of Social state would exemplify the confrontation Social state constitution-reality.

KEY WORDS: social constitutionalism, material constitution, European economic constitution.

Recibido: 01.05.2012

Aceptado: 18.10.2012 